\title{
Secondary and Tertiary Structure Formation of the $\beta$-Barrel Membrane Protein OmpA is Synchronized and Depends on Membrane Thickness
}

\author{
Jörg H. Kleinschmidt ${ }^{1,2 *}$ and Lukas K. Tamm
}

\author{
${ }^{1}$ Department of Molecular \\ Physiology and Biological \\ Physics, University of Virginia \\ Health Sciences Center \\ Charlottesville, VA 22908-0736 \\ USA \\ ${ }^{2}$ Fachbereich Biologie, Fach \\ M694, Universität Konstanz \\ D-78457 Konstanz, Germany
}

\begin{abstract}
The mechanism of membrane insertion and folding of a $\beta$-barrel membrane protein has been studied using the outer membrane protein $A$ (OmpA) as an example. OmpA forms an eight-stranded $\beta$-barrel that functions as a structural protein and perhaps as an ion channel in the outer membrane of Escherichia coli. OmpA folds spontaneously from a urea-denatured state into lipid bilayers of small unilamellar vesicles. We have used fluorescence spectroscopy, circular dichroism spectroscopy, and gel electrophoresis to investigate basic mechanistic principles of structure formation in OmpA. Folding kinetics followed a second-order rate law and is strongly depended on the hydrophobic thickness of the lipid bilayer. When OmpA was refolded into model membranes of dilaurylphosphatidylcholine, fluorescence kinetics were characterized by a rate constant that was about fivefold higher than the rate constants of formation of secondary and tertiary structure, which were determined by circular dichroism spectroscopy and gel electrophoresis, respectively. The formation of $\beta$-sheet secondary structure and closure of the $\beta$-barrel of OmpA were correlated with the same rate constant and coupled to the insertion of the protein into the lipid bilayer. OmpA, and presumably other $\beta$-barrel membrane proteins therefore do not follow a mechanism according to the two-stage model that has been proposed for the folding of $\alpha$-helical bundle membrane proteins. These different folding mechanisms are likely a consequence of the very different intramolecular hydrogen bonding and hydrophobicity patterns in these two classes of membrane proteins.
\end{abstract}

Keywords: folding kinetics; membrane protein folding; outer membrane protein A; synchronized structure formation; $\beta$-barrel membrane protein branes are relatively rare and have been mostly performed with two model proteins: bacteriorhodopsin (BR) of Halobium salinarium, ${ }^{1-6}$ and outer membrane protein A (OmpA) of Escherichia coli. $^{7-14}$ While BR is a representative $\alpha$-helical bundle protein, ${ }^{15-17}$ OmpA belongs to the class of $\beta$-barrel TMPs. In the case of BR, success of refolding has been monitored by the ability of the protein to bind its cofactor retinal. ${ }^{2}$ Refolded OmpA forms ion channels with similar conductance levels as native OmpA. ${ }^{18}$ The folding kinetics of TMPs into lipid bilayers have been studied with BR that was denatured in SDS micelles ${ }^{6}$ or with OmpA from a completely denatured state in $8 \mathrm{M}$ urea. ${ }^{10-13}$ Surrey \& Jähnig ${ }^{8}$ were the first to demonstrate the oriented insertion and folding of fully unfolded OmpA into dimyristoylphosphatidylcholine $\left(\right.$ diC $\left._{14} \mathrm{PC}\right)$ bilayers upon dilution of the denaturant 


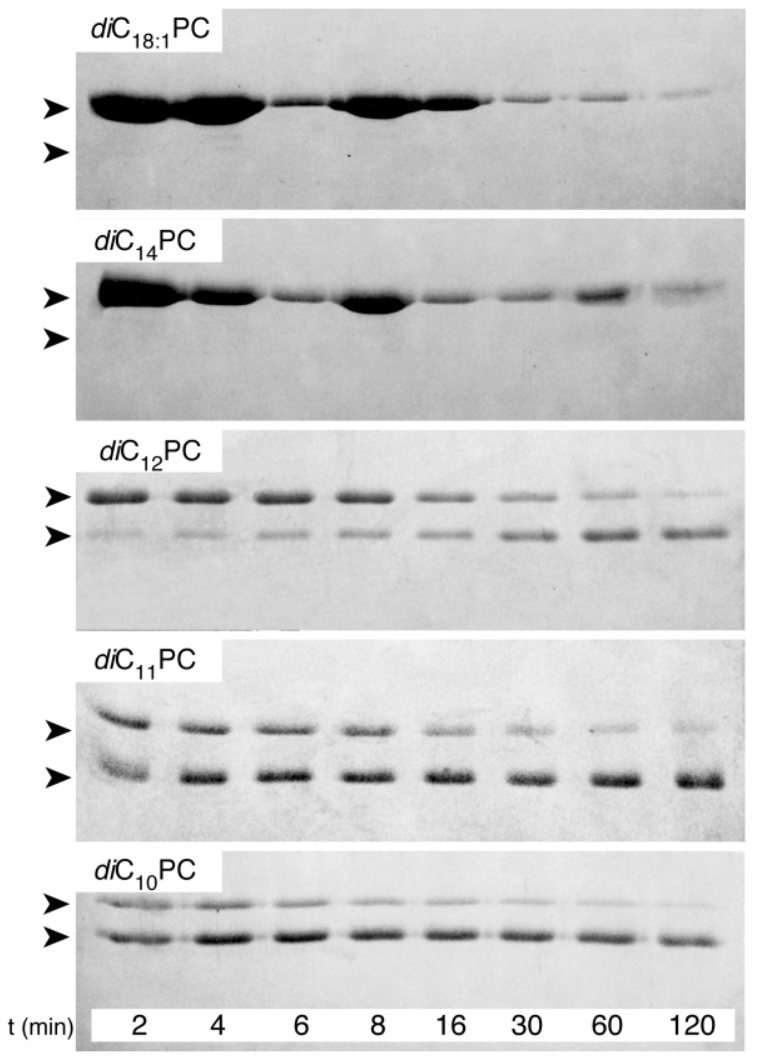

Figure 1. SDS-PAGE showing the kinetics of OmpA folding into LUV lipid bilayers of $d i \mathrm{C}_{10} \mathrm{PC}, d i \mathrm{C}_{11} \mathrm{PC}$, $d i \mathrm{C}_{12} \mathrm{PC}, d i \mathrm{C}_{14} \mathrm{PC}$ and $d i \mathrm{C}_{18: 1} \mathrm{PC}$ at $7.0 \mathrm{mM}$ lipid and $17 \mu \mathrm{M}$ OmpA. The upper arrow in each gel indicates the unfolded $35 \mathrm{kDa}$ form, the lower arrow the native $30 \mathrm{kDa}$ form of OmpA. All folding reactions were performed at $20^{\circ} \mathrm{C}$ in $150 \mu \mathrm{l}$ of $10 \mathrm{mM}$ borate buffer $(\mathrm{pH}$ 10.0), containing $2 \mathrm{mM}$ EDTA.

in absence of detergent. Folding of OmpA into lipid bilayers in vitro was successful only when the lipids were sonicated ${ }^{8,10}$ to form small unilamellar vesicles (SUVs), i.e. highly curved lipid model membranes. While the use of SUVs allows the study of membrane protein folding in vitro, their high surface curvature does not resemble the curvature of biomembranes very well.

Insertion and folding of OmpA may be facilitated in vivo by chaperones similar to those known to assist the folding of soluble proteins. The periplasmic chaperone Skp binds and solubilizes OmpA in the periplasm ${ }^{19,20}$ after OmpA is translocated across the plasma membrane by the SecA/Y/E/G export channel and after cleavage of the signal sequence. Another periplasmic protein with chaperone-like function is SurA. ${ }^{21}$ Mutants of E. coli that lack SurA, express OmpA at reduced levels. ${ }^{22}$ Whether SurA directly catalyzes the folding of OmpA is unknown. No accessory proteins of the outer membrane are known to assist the insertion of Omps. Insertion and folding of these proteins including OmpA is believed to be a spontaneous process that requires the presence of a supramolecular lipid or detergent assembly.14,23
Key problems in the study of TMP folding are, how secondary or tertiary structure formation are related to membrane insertion and whether the formation of secondary and tertiary structure are coupled or sequential processes. For example, secondary structure may first form in segments that are parallel with the bilayer surface before tertiary structure is formed and before OmpA inserts, i.e. in a hierarchical process. A second possibility is that formation of secondary structure and tertiary structure are synchronized and coupled to membrane insertion. In the present work, we therefore addressed three questions: (1) can we find conditions where OmpA refolds into lipid bilayers with low curvature, i.e. large unilamellar vesicles (LUVs); (2) are secondary and tertiary structure formation synchronized (i.e. sharing a largely similar time course) or consecutive processes; and (3) do the rates of folding depend on the hydrophobic thickness of the lipid bilayer?

\section{Results}

\section{Folding of OmpA into lipid bilayers of different} hydrophobic thickness

In a first set of experiments, we found that OmpA folds and inserts correctly into thin lipid bilayers of not only small, but also large unilamellar vesicles. All previous folding studies of OmpA had been carried out with highly curved sonicated SUVs of unsaturated phosphatidylcholines (or with detergent micelles). Refolding and insertion of OmpA was not successful when large unilamellar vesicles of these lipids were used. However, in the present study quantitative refolding could be achieved into large unilamellar vesicles of phosphatidylcholines with 12 carbon atoms or shorter fatty acyl chains. To investigate whether the bilayer thickness affects insertion and folding of OmpA, we prepared bilayers of $d i \mathrm{C}_{n} \mathrm{PCs}$ with different acyl chain lengths for folding experiments with urea-denatured OmpA. The kinetics of insertion and folding of unfolded OmpA in $8 \mathrm{M}$ urea into LUVs of $d i \mathrm{C}_{10} \mathrm{PC}, d i \mathrm{C}_{11} \mathrm{PC}, d i \mathrm{C}_{12} \mathrm{PC}$, $d i \mathrm{C}_{14} \mathrm{PC}$ and $d i \mathrm{C}_{18: 1} \mathrm{PC}$ upon strong dilution of the denaturant were analyzed by SDS-PAGE (Figure 1). Native OmpA and refolded OmpA migrate at $30 \mathrm{kDa}$, whereas unfolded OmpA migrates at $35 \mathrm{kDa}$ if not heat-denatured prior to electrophoresis. $^{24}$ The $30 \mathrm{kDa}$ form has been shown by Raman, FT-IR, and CD spectroscopy, ${ }^{7-10,14,25,26}$ by phage inactivation assays, ${ }^{24}$ and by single channel conductivity measurements ${ }^{18}$ to correspond to the native structure of OmpA. At $20^{\circ} \mathrm{C}$, OmpA only folded into bilayers of short chain lipids with 12 or fewer carbon acyl chains. Except for $d i \mathrm{C}_{14} \mathrm{PC}$, which forms bilayers in the gel phase (the lamellar-ordered phase) at $20^{\circ} \mathrm{C}$, all lipids used in this experiment form liquid-crystalline membranes at $20^{\circ} \mathrm{C}$. Even at $30^{\circ} \mathrm{C}$, i.e. above 

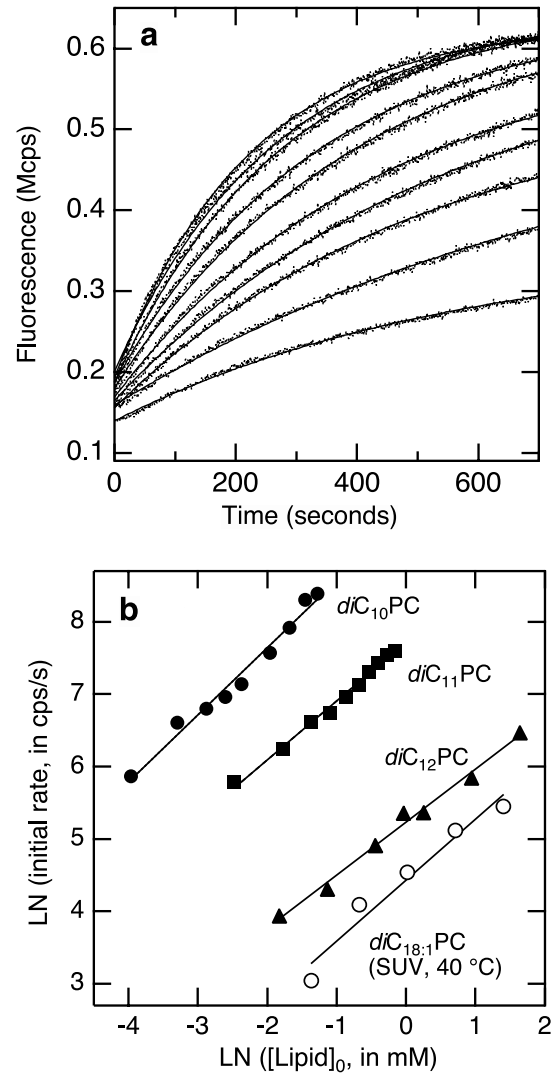

Figure 2. (a) Fluorescence time course of OmpA folding into LUV lipid bilayers of $d i \mathrm{C}_{11} \mathrm{PC}$ at concentrations of $0.08,0.17,0.25,0.34,0.42,0.51,0.59,0.67,0.76$, and $0.84 \mathrm{mM}$ (dotted lines). The OmpA concentration was $1.1 \mu \mathrm{M}$ in all experiments. All reactions were performed at $20^{\circ} \mathrm{C}$ in $1 \mathrm{ml}$ of $10 \mathrm{mM}$ borate buffer ( $\mathrm{pH} \mathrm{10.0)} \mathrm{con-}$ taining $2 \mathrm{mM}$ EDTA. The kinetics were fitted to equation (4) (continuous lines) and the fit parameters are listed in Table 1. (Mcps are mega counts per second: see Methods). (b) Double logarithmic plot of the initial rates of the OmpA folding kinetics of into $d i \mathrm{C}_{10} \mathrm{PC}$, $d i \mathrm{C}_{11} \mathrm{PC}$, and $d i \mathrm{C}_{12} \mathrm{PC}$ (LUVs) as a function of the lipid concentration $\left(T=20^{\circ} \mathrm{C}\right)$. The initial rates of OmpA folding into SUVs of $d i \mathrm{C}_{18: 1} \mathrm{PC}$ at $40^{\circ} \mathrm{C}$ are shown for comparison.

the gel to liquid-crystalline phase transition of $d i \mathrm{C}_{14} \mathrm{PC}$, OmpA did not properly fold into LUV bilayers of $d i \mathrm{C}_{14} \mathrm{PC}$ or $d i \mathrm{C}_{18: 1} \mathrm{PC}$, although it readily folded into fluid SUV bilayers of $d_{i C_{14}} \mathrm{PC}$ or $\operatorname{diC}_{18: 1} \mathrm{PC}$ at this temperature. , $^{810}$

The folding kinetics were faster when the lipid chain length was decreased from 12 to ten carbon atoms under otherwise identical experimental conditions (Figure 1). Lipids with chains of less than nine carbon atoms form micelles ${ }^{27}$ and therefore were not included in this study. Insertion of OmpA into $d i \mathrm{C}_{10} \mathrm{PC}$ bilayers did not affect the lamellar bilayer structure, as verified by ${ }^{31} \mathrm{P}$ NMR spectroscopy. ${ }^{27}$

To further investigate the dependence of OmpA folding on the lipid chain length, we determined the folding kinetics into bilayers of $d i \mathrm{C}_{10} \mathrm{PC}$, $d i \mathrm{C}_{11} \mathrm{PC}, d i \mathrm{C}_{12} \mathrm{PC}, d i \mathrm{C}_{14} \mathrm{PC}, d i \mathrm{C}_{18: 1} \mathrm{PC}$ and in aqueous buffer by fluorescence spectroscopy. Changes in Trp fluorescence report on the first insertion of the Trp residues into the apolar environment of the lipid bilayer ${ }^{11}$. After rapid dilution of ureadenatured OmpA either into buffer or into a solution of LUVs of $d i \mathrm{C}_{18: 1} \mathrm{PC}$ or $d i \mathrm{C}_{14} \mathrm{PC}$, the fluorescence of $\mathrm{OmpA}$ at $330 \mathrm{~nm}$ increased very quickly in less than five seconds to $\sim 160,000 \mathrm{cps}$ (counts per second), i.e. to $\sim 160 \%$ of the intensity of unfolded OmpA in $8 \mathrm{M}$ urea at the same OmpA concentration and temperature. The fluorescence intensity then remained constant for several minutes (data not shown). This observation was reported for $\mathrm{LUVs}$ of $\operatorname{diC}_{14} \mathrm{PC}$ at $30{ }^{\circ} \mathrm{C} .{ }^{10}$ However, when we used LUVs of short chain phospholipids, we observed an additional fluorescence increase, as shown for $d i C_{11} \mathrm{PC}$ in Figure 2(a). The fluorescence kinetics demonstrate that the rate of this phase of OmpA folding increases with the concentration of the phospholipid. Similar to the folding experiments monitored by SDS-PAGE, the fastest kinetics were observed for $d i \mathrm{C}_{10} \mathrm{PC}$ bilayers and the folding rates decreased with increasing chain length of the lipid. To observe comparable folding rates, we had to increase the concentrations of the lipids with the longer chains. The concentrations ranged from $0.02 \mathrm{mM}$ to $0.28 \mathrm{mM}$ for $d i \mathrm{C}_{10} \mathrm{PC}, 0.08 \mathrm{mM}$ to $0.84 \mathrm{mM}$ for $d i \mathrm{C}_{11} \mathrm{PC}$, and $0.16 \mathrm{mM}$ to $5.15 \mathrm{mM}$ for $\operatorname{diC}_{12} \mathrm{PC}$.

\section{Determination of the rate law}

In many previous studies, particularly in binding studies of amphipathic peptides to lipid bilayers, it was assumed that folding and insertion of membrane proteins and peptides is a partitioning process, which follows first-order kinetics or multi-step first-order kinetics. ${ }^{10,11,28,29}$ If this were the case, the kinetics of OmpA folding should depend on protein concentration, but should be independent of lipid concentrations. The data of Figure 2(a) clearly show that OmpA folding depends strongly on the lipid concentration. Since there are no previous reports that include an experimental test of the order of a membrane protein folding reaction, we determined the rate law of OmpA folding into lipid bilayers using the method of initial rates, as described in Methods.

We first resolved the order of the folding reaction with respect to lipid by analyzing the data of Figure 2(a) with a double-logarithmic plot of the initial rate as a function of the lipid concentration (Figure 2(b)). For comparison, we also show in this Figure similar data of OmpA folding into SUVs of $d_{i C_{18: 1}} \mathrm{PC}$ at $40{ }^{\circ} \mathrm{C}$. For all lipids, these plots indicated linear dependencies of the logarithm of the initial rate on the logarithm of the lipid concentration. The slopes of the linear fits shown in Figure 2(b) were $0.93 \pm 0.05$ for $d_{i j} \mathrm{C}_{10} \mathrm{PC}, 0.81 \pm 0.03$ for $d i \mathrm{C}_{11} \mathrm{PC}, 0.73 \pm 0.03$ for $d_{i C_{12}} \mathrm{PC}$ and $0.84 \pm 0.1$ for SUVs of $\operatorname{diC}_{18: 1} \mathrm{PC}$. Therefore, OmpA folding is of first-order with 

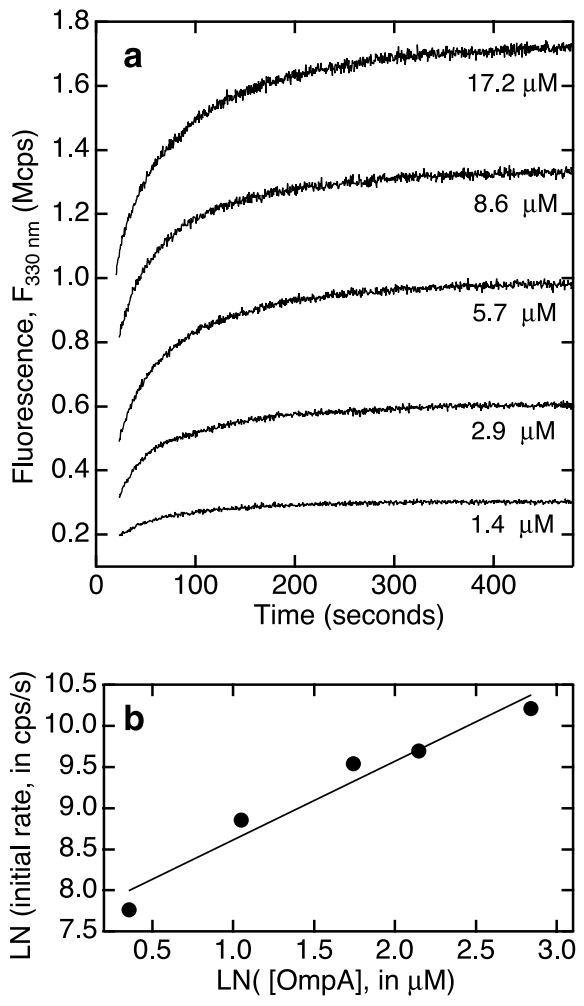

Figure 3. Folding kinetics of OmpA as a function of protein concentration monitored by $\operatorname{Trp}$ fluorescence at $20^{\circ} \mathrm{C}$. (a) Fluorescence time courses at $1.1 \mathrm{mM}$ lipid and $1.43 \mu \mathrm{M}, 2.9 \mu \mathrm{M}, 5.7 \mu \mathrm{M}, 8.6 \mu \mathrm{M}$, and $17.2 \mu \mathrm{M}$ OmpA. (b) Double logarithmic plot of the initial rates of the kinetics of panel A as a function of protein concentration. The linear fit had a slope of $0.96 \pm 0.12$, indicating firstorder dependence of the folding kinetics on the OmpA concentration.

respect to lipid. Figure 2(b) shows the strong dependence of OmpA folding on the hydrophobic thickness of the lipid bilayer over a wide range of lipid concentrations. OmpA folding into SUVs of ${ }^{2} \mathrm{C}_{18: 1} \mathrm{PC}$ at $40^{\circ} \mathrm{C}$, despite the higher temperature, was slower than folding of OmpA into LUVs of the short-chain phospholipids at $20^{\circ} \mathrm{C}$.

The order of the reaction with respect to OmpA was determined from fluorescence kinetics at different OmpA concentrations, but at a fixed concentration of $d i \mathrm{C}_{10} \mathrm{PC}$ (Figure 3(a)). A linear fit of the double-logarithmic plot of the initial rates as a function of the initial concentration of unfolded OmpA (Figure 3(b)) had the slope of $0.96 \pm 0.12$, indicating first-order folding with respect to OmpA. Since the folding reaction was also of first-order with respect to lipid, the insertion and folding of OmpA is described by a rate law of second-order (equation (4); Methods). The fits shown in Figures 2(a) and 3(a) indicate that the second-order rate law describes the fluorescence kinetics of OmpA folding into bilayers of shortchain lipids to a good approximation. All fit parameters are given in Table 1 . The second-order rate constant was lowest for $\operatorname{diC}_{12} \mathrm{PC} \quad(\approx 0.3-$ $\left.0.51 \mathrm{~mol}^{-1} \mathrm{~s}^{-1}\right)$ and highest for $\mathrm{diC}_{10} \mathrm{PC}(\approx 30-$ $\left.501 \mathrm{~mol}^{-1} \mathrm{~s}^{-1}\right)$. The decrease of the second-order rate constant was slightly less than an order of magnitude between $d i \mathrm{C}_{10} \mathrm{PC}$ and $d i \mathrm{C}_{11} \mathrm{PC}$, but more than an order of magnitude between $d i \mathrm{C}_{11} \mathrm{PC}$ and $d i \mathrm{C}_{12} \mathrm{PC}$. If the second-order rate law describes the reaction accurately, the rate constants must be independent of the concentrations of lipid and OmpA. This was indeed the case for most data listed in Table 1. Only when the lipid/protein ratios were very low ( $\left.\mathrm{L} / \mathrm{P}<90 \mathrm{~mol} \mathrm{~mol}^{-1}\right)$, deviations from the second-order rate law, i.e. concentration-dependent rate constants $k_{2 \text {.ord }}$ were found. We did not attempt to find the reasons for these deviations under extreme conditions and we conclude that second-order kinetics describe this phase of OmpA folding into lipid bilayers accurately as long as the $\mathrm{L} / \mathrm{P}$ ratios are not too low.

The fluorescence coefficient for the aqueous form of OmpA was consistently in the range of $80,000-120,000$ cps, while the fluorescence coefficients for lipid-bound OmpA ranged from $400,000 \mathrm{cps}$ to $500,000 \mathrm{cps}$ for $d i \mathrm{C}_{11} \mathrm{PC}$ and $d i \mathrm{C}_{12} \mathrm{PC}$, but around $200,000 \mathrm{cps}$ to $360,000 \mathrm{cps}$ for $d i \mathrm{C}_{10} \mathrm{PC}$. A likely explanation for the lower fluorescence of refolded OmpA in ${ }^{2} \mathrm{C}_{10} \mathrm{PC}$ is that the Trp residues of OmpA are exposed to a more polar environment at the membrane/water interface in $d i \mathrm{C}_{10} \mathrm{PC}$ than in $d i \mathrm{C}_{11} \mathrm{PC}$ or $d i \mathrm{C}_{12} \mathrm{PC}$ bilayers.

Although the second-order rate law describes very well the folding kinetics of OmpA, monoexponential fits of the time courses of folding were in most cases just as good. Since the lipid concentration was much higher than the protein concentration, we suspected that the kinetics could be of pseudo-first-order with a rate constant $k_{\text {ps.1.ord }}=[L] \times k_{2 \text {.ord }}$. Therefore, we compared the rate constants obtained from a mono-exponential fit and divided by the lipid concentration with the second-order rate constant in Table 1 . The data show that OmpA folding can be described as a pseudo-first-order reaction. The pseudo-first-order rate constants depend on the lipid concentration. However, when normalized by the lipid concentration, second-order rate constants are obtained that closely resemble those obtained directly from fits to the second-order rate law (Table 1). Therefore, it is best to use the second-order rate constants to compare OmpA folding into different membranes or to compare folding events of OmpA investigated by different methods requiring different OmpA or lipid concentrations.

\section{Rate of tertiary structure formation}

Fluorescence kinetics of OmpA folding into bilayers monitor changes in the polarity of the environment of the fluorescent Trp residues. To obtain the kinetics of tertiary structure formation in OmpA, we analyzed the fraction of folded OmpA at specific times after initiation of folding by electrophoresis as described. ${ }^{8,11}$ Figure 4(a) shows the SDS-PAGE analysis of the time courses of OmpA folding into LUVs at various 
Table 1. Rate constants of the folding of OmpA by fluorescence spectroscopy

\begin{tabular}{|c|c|c|c|c|c|c|c|c|c|c|}
\hline $\begin{array}{l}\text { A. } \operatorname{dic}_{12} P C \\
\text { Lipid/OmpA molar ratio } \\
c\left(d i \mathrm{C}_{12} \mathrm{PC}\right)(\mathrm{mM}) \\
c(\mathrm{OmpA})(\mu \mathrm{M})\end{array}$ & $\begin{array}{l}141 \\
0.16 \\
1.14\end{array}$ & $\begin{array}{l}281 \\
0.32 \\
1.14\end{array}$ & $\begin{array}{l}563 \\
0.64 \\
1.14\end{array}$ & $\begin{array}{l}844 \\
0.96 \\
1.14\end{array}$ & $\begin{array}{l}1126 \\
1.29 \\
1.14\end{array}$ & $\begin{array}{l}2251 \\
2.57 \\
1.14\end{array}$ & $\begin{array}{l}4502 \\
5.15 \\
1.14\end{array}$ & & & \\
\hline $\begin{array}{l}\text { Second-order fit } \\
k_{2 . \text { ord }}\left(1 \mathrm{~mol}^{-1} \mathrm{~s}^{-1}\right)^{\mathbf{b}} \\
F_{\mathrm{L}}{ }^{\mathrm{c}}\left(\mathrm{Mcps} \mathrm{mM}^{-1}\right) \\
F_{\mathrm{W}} \mathrm{d}^{\mathrm{d}}\left(\mathrm{Mcps} \mathrm{mM}^{-1}\right)\end{array}$ & $\begin{array}{c}0.47 \\
658 \\
64\end{array}$ & $\begin{array}{l}0.49 \\
523 \\
68\end{array}$ & $\begin{array}{c}0.59 \\
390 \\
74\end{array}$ & $\begin{array}{c}0.466 \\
407 \\
81\end{array}$ & $\begin{array}{c}0.32 \\
532 \\
82\end{array}$ & $\begin{array}{l}0.36 \\
430 \\
107\end{array}$ & $\begin{array}{l}0.31 \\
482 \\
137\end{array}$ & & & \\
\hline $\begin{array}{l}\text { First-order fit } \\
k_{\text {ps.1.ord }}\left(\mathrm{s}^{-1}\right) \times 10^{3 \mathrm{e}} \\
k_{\text {2.ord }}^{*}\left(1 \mathrm{~mol}^{-1} \mathrm{~s}^{-1}\right)^{\mathrm{f}}\end{array}$ & $\begin{array}{c}0.0705 \\
0.44\end{array}$ & $\begin{array}{l}0.11 \\
0.34\end{array}$ & $\begin{array}{l}0.48 \\
0.75\end{array}$ & $\begin{array}{l}0.36 \\
0.38\end{array}$ & $\begin{array}{l}0.40 \\
0.31\end{array}$ & $\begin{array}{l}0.90 \\
0.35\end{array}$ & $\begin{array}{c}1.5 \\
0.30\end{array}$ & & & \\
\hline $\begin{array}{l}\text { B. } \operatorname{diC}_{11} P C \\
\text { Lipid/OmpA molar ratio } \\
c\left(\text { diC }_{11} \mathrm{PC}\right)(\mathrm{mM}) \\
c(\text { OmpA) }(\mu \mathrm{M})\end{array}$ & $\begin{array}{l}74 \\
0.08 \\
1.14\end{array}$ & $\begin{array}{l}148 \\
0.17 \\
1.14\end{array}$ & $\begin{array}{l}222 \\
0.25 \\
1.14\end{array}$ & $\begin{array}{l}295 \\
0.34 \\
1.14\end{array}$ & $\begin{array}{l}369 \\
0.42 \\
1.14\end{array}$ & $\begin{array}{l}443 \\
0.51 \\
1.14\end{array}$ & $\begin{array}{l}517 \\
0.59 \\
1.14\end{array}$ & $\begin{array}{l}591 \\
0.67 \\
1.14\end{array}$ & $\begin{array}{l}665 \\
0.76 \\
1.14\end{array}$ & $\begin{array}{l}739 \\
0.84 \\
1.14\end{array}$ \\
\hline $\begin{array}{l}\text { Second-order fit } \\
k_{2 . \text { ord }}\left(\mathrm{mol}^{-1} \mathrm{~s}^{-1}\right) \\
F_{\mathrm{L}}\left(\mathrm{Mcps} \mathrm{mM}^{-1}\right) \\
F_{\mathrm{W}}\left(\mathrm{Mcps} \mathrm{mM}^{-1}\right)\end{array}$ & $\begin{array}{l}20.7 \\
277 \\
84\end{array}$ & $\begin{array}{l}6.9 \\
430 \\
83\end{array}$ & $\begin{array}{l}7.6 \\
420 \\
82\end{array}$ & $\begin{array}{l}5.3 \\
474 \\
79\end{array}$ & $\begin{array}{l}5.3 \\
469 \\
83\end{array}$ & $\begin{array}{c}4.9 \\
499 \\
82\end{array}$ & $\begin{array}{c}5.0 \\
490 \\
90\end{array}$ & $\begin{array}{c}5.3 \\
494 \\
89\end{array}$ & $\begin{array}{l}5.0 \\
492 \\
100\end{array}$ & $\begin{array}{c}5.3 \\
483 \\
99\end{array}$ \\
\hline $\begin{array}{l}\text { First-order fit } \\
k_{\text {ps.1.ord }}\left(\mathrm{s}^{-1}\right) \times 10^{3} \\
k_{\text {2.ord }}^{*}\left(\mathrm{l} \mathrm{mol}^{-1} \mathrm{~s}^{-1}\right)\end{array}$ & $\begin{array}{c}1.7 \\
21.8\end{array}$ & $\begin{array}{l}1.2 \\
6.9\end{array}$ & $\begin{array}{l}1.9 \\
7.6\end{array}$ & $\begin{array}{l}1.8 \\
5.3\end{array}$ & $\begin{array}{l}2.2 \\
5.2\end{array}$ & $\begin{array}{l}2.5 \\
4.9\end{array}$ & $\begin{array}{l}3.0 \\
5.1\end{array}$ & $\begin{array}{l}3.5 \\
5.2\end{array}$ & $\begin{array}{l}3.8 \\
5.0\end{array}$ & $\begin{array}{l}4.5 \\
5.4\end{array}$ \\
\hline $\begin{array}{l}\text { C. } \operatorname{diC}_{10} P C \\
\text { Lipid/OmpA molar ratio } \\
c\left(\operatorname{diC}_{10} \mathrm{PC}\right)(\mathrm{mM}) \\
c(\mathrm{OmpA})(\mu \mathrm{M})\end{array}$ & $\begin{array}{l}16 \\
0.02 \\
1.14\end{array}$ & $\begin{array}{c}33 \\
0.04 \\
1.14\end{array}$ & $\begin{array}{c}49 \\
0.06 \\
1.14\end{array}$ & $\begin{array}{c}65 \\
0.07 \\
1.14\end{array}$ & $\begin{array}{c}82 \\
0.09 \\
1.14\end{array}$ & $\begin{array}{l}122 \\
0.14 \\
1.14\end{array}$ & $\begin{array}{l}163 \\
0.19 \\
1.14\end{array}$ & $\begin{array}{l}204 \\
0.23 \\
1.14\end{array}$ & $\begin{array}{l}245 \\
0.28 \\
1.14\end{array}$ & \\
\hline $\begin{array}{l}\text { Second-order fit } \\
k_{2 . \text { ord }}\left(\mathrm{lmol}^{-1} \mathrm{~s}^{-1}\right) \\
F_{\mathrm{L}}\left(\mathrm{Mcps} \mathrm{mM}^{-1}\right) \\
F_{\mathrm{W}}\left(\mathrm{Mcps} \mathrm{mM}^{-1}\right)\end{array}$ & $\begin{array}{l}182.5 \\
134 \\
101\end{array}$ & $\begin{array}{l}129.1 \\
157 \\
99\end{array}$ & $\begin{array}{l}81.6 \\
176 \\
100\end{array}$ & $\begin{array}{l}58.0 \\
202 \\
103\end{array}$ & $\begin{array}{l}45.7 \\
218 \\
102\end{array}$ & $\begin{array}{c}34.8 \\
255 \\
95\end{array}$ & $\begin{array}{c}31.2 \\
267 \\
96\end{array}$ & $\begin{array}{l}24.7 \\
333 \\
101\end{array}$ & $\begin{array}{l}29.5 \\
367 \\
143\end{array}$ & \\
\hline $\begin{array}{l}\text { First-order fit } \\
k_{\text {ps.1.ord }}\left(\mathrm{s}^{-1}\right) \\
k_{\text {2.ord }}^{*}\left(\mathrm{l} \mathrm{mol}^{-1} \mathrm{~s}^{-1}\right)\end{array}$ & $\begin{array}{c}3.7 \\
184.0\end{array}$ & $\begin{array}{c}4.5 \\
112.5\end{array}$ & $\begin{array}{c}4.4 \\
73.3\end{array}$ & $\begin{array}{c}3.8 \\
54.3\end{array}$ & $\begin{array}{c}4.0 \\
44.0\end{array}$ & $\begin{array}{c}4.7 \\
33.6\end{array}$ & $\begin{array}{l}5.7 \\
30\end{array}$ & $\begin{array}{c}5.9 \\
25.5\end{array}$ & $\begin{array}{c}8.5 \\
30.4\end{array}$ & \\
\hline
\end{tabular}

a Fluorescence kinetics of Figure 2(a) were fit to equation (5) assuming that fluorescence emissions of the folded and unfolded species at $330 \mathrm{~nm}$ are proportional to the concentrations of the respective species, i.e. to the function $F=F_{\mathrm{W}}\left[P_{\mathrm{U}}\right](t)+F_{\mathrm{L}}\left[P_{\mathrm{F}}\right](t)+$ const. Fit parameters shown in italic typeface were obtained from the fit. The lipid and protein concentrations were invariable parameters in all fits.

b $k_{\text {2.ord: }}$ second-order rate constant.

c $F_{\mathrm{L}}$ : fluorescence coefficient of the membrane-adsorbed OmpA.

d $F_{\mathrm{W}}$ : fluorescence coefficient of the aqueous OmpA.

e Pseudo first-order rate constants ( $k_{\text {ps.1.ord. }}$ ) of fluorescence kinetics of Figure 2(a) obtained from a mono-exponential fit.

f Calculated second-order rate constant from the pseudo-first-order rate constant according to: $k_{2 \text {.ord }}^{*}=k_{\mathrm{ps} .1 \text {.ord. }} /[L]$.

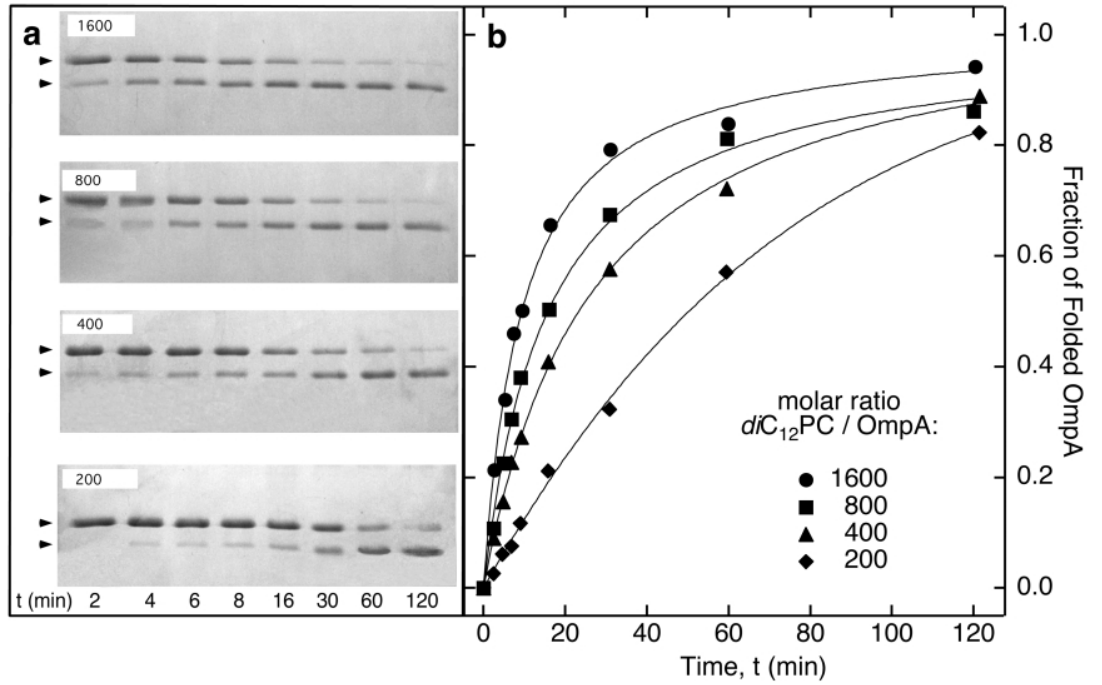

Figure 4. Folding kinetics of OmpA as a function of lipid concentration measured by SDS-PAGE. (a) OmpA folding into diC $\mathrm{C}_{12} \mathrm{PC}$ analyzed by SDS-PAGE at $28.1 \mathrm{mM}$, $14.1 \mathrm{mM}, 7.0 \mathrm{mM}$, and $3.5 \mathrm{mM}$ lipid (from the top to the bottom gel). The OmpA concentration was $17.0 \mu \mathrm{M}$. The gels show that OmpA folded fastest at the highest $\mathrm{L} / \mathrm{P}$ ratio, as indicated by the faster appearance of the $30 \mathrm{kDa}$ folded form of OmpA. (b) The fractions of folded OmpA determined by densitometry from the gels in (a) are plotted as a function of time and fitted to equation (4) (continuous lines). The fit parameters are listed in Table 2 . 
Table 2. Second-order rate constants of secondary and tertiary structure formation

\begin{tabular}{|c|c|c|c|c|}
\hline \multicolumn{5}{|c|}{$\begin{array}{l}\text { A. OmpA folding detected by SDS-PAGE } \\
\text { Second-order fit }\end{array}$} \\
\hline Lipid/OmpA molar ratio & 1653 & 829 & 412 & 206 \\
\hline$c(\mathrm{OmpA})(\mu \mathrm{M})$ & 17.0 & 17.0 & 17.0 & 17.0 \\
\hline$d i \mathrm{C}_{12} \mathrm{PC}(\mathrm{mM})$ & 28.1 & 14.1 & 7.0 & 3.5 \\
\hline$k_{2 . o r d}\left(1 \mathrm{~mol}^{-1} \mathrm{~s}^{-1}\right)$ & $0.053 \pm 0.003$ & $0.070 \pm 0.003$ & $0.090 \pm 0.006$ & $0.095 \pm 0.005$ \\
\hline Yield (\%) & $87.7 \pm 2.2$ & $84.0 \pm 1.6$ & $85.8 \pm 0.03$ & $104.0 \pm 4$ \\
\hline $\begin{array}{l}\text { First-order fit } \\
k_{\text {ps.1.ord }}\left(10^{-3} \mathrm{~s}^{-1}\right)^{\mathbf{b}} \\
k^{*}{ }_{2 \text { ord }}\left(1 \mathrm{~mol}^{-1} \mathrm{~s}^{-1}\right)^{\mathbf{c}}\end{array}$ & $\begin{array}{c}1.4 \pm 0.1 \\
0.051 \pm 0.005\end{array}$ & $\begin{array}{c}0.96 \pm 0.07 \\
0.068 \pm 0.005\end{array}$ & $\begin{aligned} 0.59 & \pm 0.06 \\
0.084 & \pm 0.008\end{aligned}$ & $\begin{array}{c}0.22 \pm 0.02 \\
0.063 \pm 0.005\end{array}$ \\
\hline \multicolumn{5}{|c|}{ B. OmpA folding detected by CD spectroscopy ${ }^{\mathrm{d}}$} \\
\hline Lipid/OmpA molar ratio & 4129 & 1387 & 677 & 355 \\
\hline$c(\mathrm{OmpA})(\mu \mathrm{M})$ & 3.1 & 3.1 & 3.1 & 3.1 \\
\hline$d_{i 2} \mathrm{C}_{12} \mathrm{PC}(\mathrm{mM})$ & 12.8 & 4.3 & 2.1 & 1.1 \\
\hline$k_{2 \text {.ord }}\left(1 \mathrm{~mol}^{-1} \mathrm{~s}^{-1}\right)$ & $0.095 \pm 0.003$ & $0.093 \pm 0.005$ & $0.083 \pm 0.03$ & $0.083 \pm 0.02$ \\
\hline $\mathrm{CD}_{\mathrm{W}}^{\mathrm{e}}$ & -2236 & -2200 & -1006 & -3411 \\
\hline $\mathrm{CD}_{\mathrm{L}}^{\mathrm{f}}$ & -10227 & -10883 & -11664 & -12743 \\
\hline \multicolumn{5}{|l|}{ First-order fit } \\
\hline$k_{\text {ps.1.ord }}\left(10^{-3} \mathrm{~s}^{-1}\right)$ & $1.09 \pm 0.09$ & $0.38 \pm 0.03$ & $0.11 \pm 0.07$ & $0.05 \pm 0.02$ \\
\hline$k_{2 . \text { ord }}^{*}\left(1 \mathrm{~mol}^{-1} \mathrm{~s}^{-1}\right)$ & $0.086 \pm 0.01$ & $0.09 \pm 0.03$ & $0.053 \pm 0.004$ & $0.04 \pm 0.02$ \\
\hline \multicolumn{5}{|c|}{ 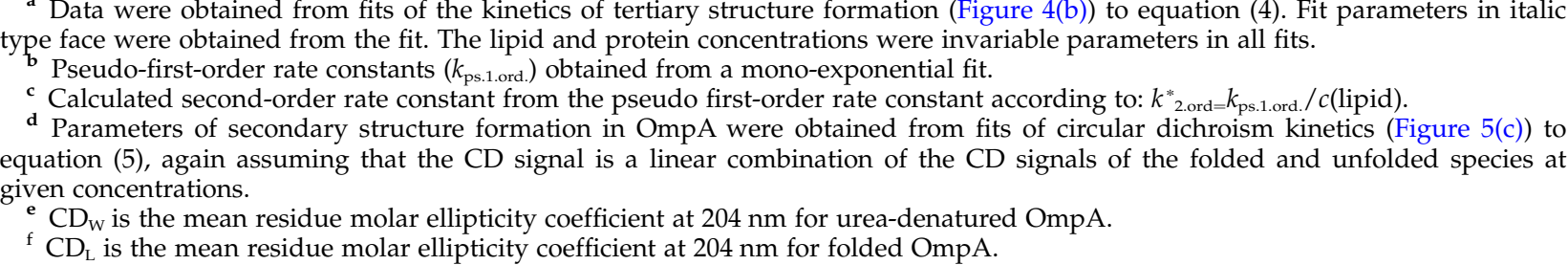 } \\
\hline
\end{tabular}

concentrations of $d i \mathrm{C}_{12} \mathrm{PC}$. The densitometrically determined fractions of folded OmpA as a function of the time after initiation of folding are shown in Figure 4(b). The concentration dependence was evaluated by the method of initial rates. A doublelogarithmic plot of the initial rate versus the initial concentration of $d i \mathrm{C}_{12} \mathrm{PC}$ showed a linear dependence with a slope of $0.89 \pm 0.15$, again indicating a second-order rate law. The kinetics of tertiary structure formation are well described by nonlinear least-squares fits to the second-order rate law (equation (4)) as shown in Figure 4(b). The second-order rate constants for the individual fits and the yields of fully folded OmpA are given in Table 2(A). The average second-order rate constant was $0.08( \pm 0.02) 1 \mathrm{~mol}^{-1} \mathrm{~s}^{-1}$, i.e. about five times smaller than the average second-order rate constant of $0.42( \pm 0.1) 1 \mathrm{~mol}^{-1} \mathrm{~s}^{-1}$, obtained from fluorescence spectroscopy. Therefore, the formation of tertiary structure succeeds the insertion of the Trp residues into the lipid bilayer.

\section{Rate of secondary structure formation}

We also investigated the kinetics of secondary structure formation of OmpA as a function of lipid concentration and chain length by CD spectroscopy. CD spectra of native, unfolded, and refolded OmpA indicated that monitoring the ellipticity at $204 \mathrm{~nm}$ would result in the best signal/noise ratio in kinetic experiments (Figure 5(a)). CD spectra of refolded (four hours) OmpA in $d i \mathrm{C}_{10} \mathrm{PC}, d_{i 1} \mathrm{C}_{11} \mathrm{PC}$, or $d i \mathrm{C}_{12} \mathrm{PC}$ were quite similar to previously published $C D$ spectra of native and refolded OmpA.,10,25 The CD spectrum of OmpA refolded into $d i \mathrm{C}_{10} \mathrm{PC}$ is shown in Figure 5(a) (continuous line). The spectrum has a maximum at $\sim 200 \mathrm{~nm}$ with a reduced amplitude compared to native OmpA. This is most likely caused by the strong absorption of residual urea, which affects the shape of the CD spectrum below $\sim 202 \mathrm{~nm}$. A $\mathrm{CD}$ spectrum recorded after removal of urea by dialysis of refolded OmpA indicated complete refolding. In contrast to $\mathrm{OmpA}$ in $d i \mathrm{C}_{10} \mathrm{PC}$, the $\mathrm{CD}$ spectra of OmpA in the presence of LUVs of $d i \mathrm{C}_{14} \mathrm{PC}$ or $d i \mathrm{C}_{18: 1} \mathrm{PC}$ were quite similar to those of misfolded OmpA in water and indicated that no major changes in secondary structure occurred as a result of the presence of the long-chain phospholipids $d i \mathrm{C}_{14} \mathrm{PC}$ or $d i \mathrm{C}_{18: 1} \mathrm{PC}$ during the first 30 minutes of folding. The kinetics of secondary structure formation in OmpA were recorded at $204 \mathrm{~nm}$ after mixing unfolded OmpA with LUVs of $d i \mathrm{C}_{10} \mathrm{PC}, d i \mathrm{C}_{11} \mathrm{PC}, d i \mathrm{C}_{12} \mathrm{PC}, d i \mathrm{C}_{14} \mathrm{PC}$, and $d i \mathrm{C}_{18: 1} \mathrm{PC}$ (Figure $5(\mathrm{~b})$ ). The kinetics depended again quite strongly on bilayer thickness. In $d i \mathrm{C}_{10} \mathrm{PC}$, secondary structure formation was essentially complete within the mixing time of the experiment. Completion in $d i \mathrm{C}_{11} \mathrm{PC}$ required $\sim 20$ minutes and completion in $d_{i C_{12}} \mathrm{PC}>60$ minutes at $2.1 \mathrm{mM}$ lipid (Figure 5(b)). Secondary structure formation again depended on the lipid concentration, as 


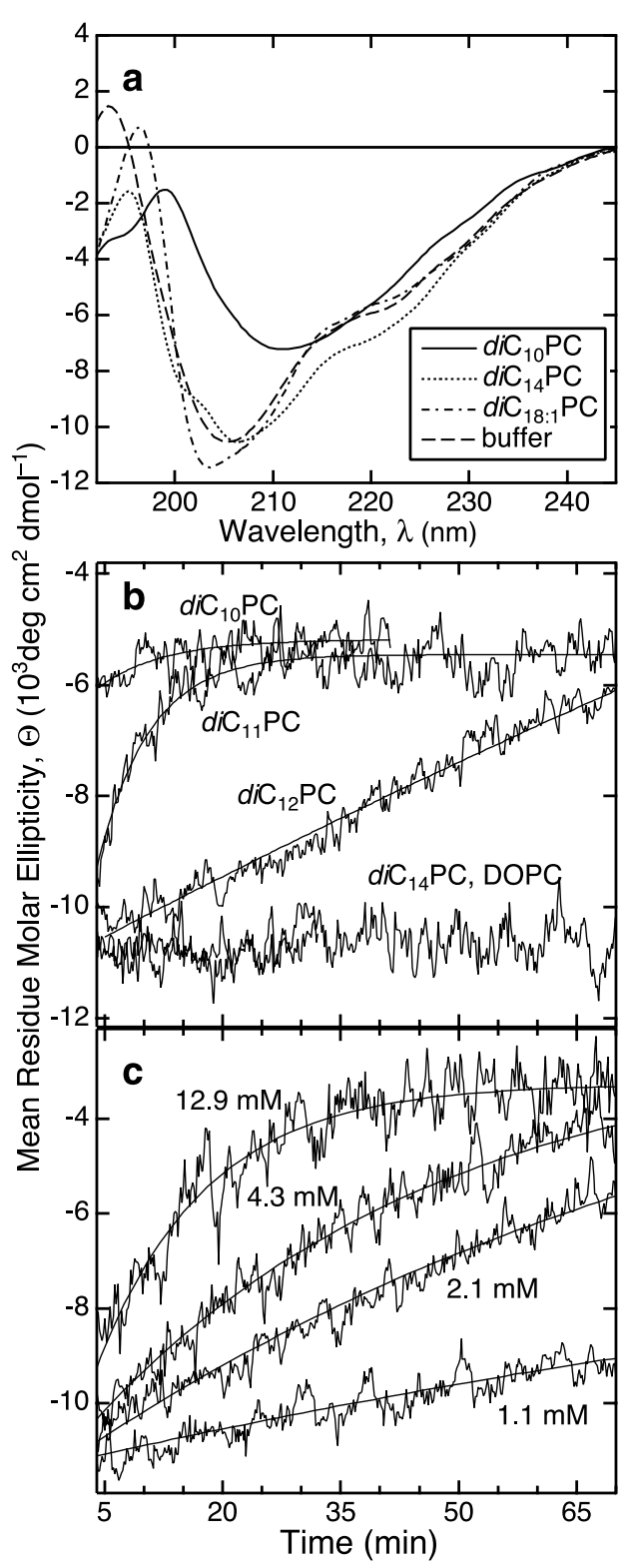

Figure 5. Folding of OmpA measured by CD spectroscopy. (a) CD spectra of OmpA in buffer (broken line), in presence of LUVs of $d i \mathrm{C}_{14} \mathrm{PC}$ (dotted line), $d i \mathrm{C}_{18: 1} \mathrm{PC}$ (broken-dotted line) and $d_{i C_{10}} \mathrm{PC}$ (continuous line). Spectra were acquired 30 minutes after initiation of folding (and in addition after four hours, data not shown) and indicate major changes in secondary structure of OmpA only in presence of $d i \mathrm{C}_{10} \mathrm{PC}$. (b) Time course of the circular dichroism at $204 \mathrm{~nm}$ monitoring secondary structure changes in OmpA at lipid concentrations of $2.1 \mathrm{mM}$. The kinetics of secondary structure formation depended on the hydrophobic chain length of the lipid. (c) Time course of the circular dichroism at $204 \mathrm{~nm}$ of OmpA folding into $12.8,4.3,2.1$, and $1.1 \mathrm{mM}$ (from top to bottom) LUVs of $d_{i C_{12}}$ PC. All kinetics were fitted to equation (5) (smooth lines). The fit parameters are listed in Table 2.

shown for the case of $d i \mathrm{C}_{12} \mathrm{PC}$ in Figure 5(c). Double logarithmic plots of the initial rates versus the initial concentration of $d i \mathrm{C}_{12} \mathrm{PC}$ had a slope of $0.86 \pm 0.12$, indicating that the kinetics of second- ary structure formation were also of second-order. We therefore fitted the kinetics to the second-order rate law (equation (5)) to determine the rate constants listed in Table 2(B). The best fits are shown as smooth lines in Figure 5(c) and the rate constants are listed in Table 2(B). The average second-order rate constant was $0.08( \pm 0.01)$ $1 \mathrm{~mol}^{-1} \mathrm{~s}^{-1}$ and virtually the same as the secondorder rate constant of tertiary structure formation $\left(0.08( \pm 0.02) 1 \mathrm{~mol}^{-1} \mathrm{~s}^{-1}\right)$ in $d i \mathrm{C}_{12} \mathrm{PC}$ bilayers. Therefore, secondary and tertiary structures are formed simultaneously as OmpA folds into $d i \mathrm{C}_{12} \mathrm{PC}$ lipid bilayers.

\section{Discussion}

Our detailed kinetic study of OmpA folding into thin phosphatidylcholine bilayers yielded three major new results that will be discussed in separate sections below. First, the kinetics of insertion and folding of OmpA into bilayers of short-chain phospholipids are well approximated by a singlestep second-order rate law. Second, the kinetics of OmpA folding depends strongly on the hydrophobic thickness of the lipid bilayer. And third, the kinetics of secondary and tertiary structure formation of OmpA are correlated as demonstrated by indistinguishable second-order rate constants that are four to five times slower than the kinetics of Trp insertion into the lipid bilayer observed by fluorescence spectroscopy.

\section{Second-order rate law of membrane protein folding}

Folding of OmpA into lipid bilayers follows a rate law of second-order as determined by the method of initial rates with different analytical methods: fluorescence spectroscopy, CD spectroscopy, and SDS-gel electrophoresis. Second-order rate constants derived from fits to the integrated second-order rate law (equation (4)) are listed in Tables 1 and 2. Each folding reaction can also be described by pseudo-first-order kinetics at a given lipid concentration. The pseudo-first-order rate constants depend on the lipid concentrations (Tables 1 and 2), but the second-order rate constant can be calculated from mono-exponential fits with the relation $k_{2 \text {.ord }}=k_{\text {ps.1.ord }} /[L]$. The second-order rate constants determined by the two methods are very similar to each other, and importantly, are independent of the lipid and protein concentrations. Unfolded OmpA solubilized in $8 \mathrm{M}$ urea does not show any significant residual secondary structure by CD. ${ }^{8,14}$ Therefore, OmpA folding into bilayers of short-chain phospholipids can be studied in a single reaction step without the need of a partially folded intermediate in detergent and without complications of micelle-bilayer mixing that are encountered in other systems of TMP folding. This greatly facilitates the determination of the order of the folding reaction of OmpA and possibly 
other $\beta$-barrel TMPs. The observation of secondorder kinetics also simplifies studies on the effects of the properties of the lipid bilayer on the folding of TMPs, because absolute rate constants that are independent of concentrations and methods of observation can now be compared directly in different bilayer systems.

We observed deviations from the second-order rate law at high protein and low lipid concentrations (L/P <90; Table 1$)$. This may be due to protein-protein interactions that are not accounted for in our simple reaction scheme. To cover the hydrophobic circumference of folded OmpA less than 11-12 lipids (or 22-24 lipids per bilayer) are needed to solvate OmpA (estimates for liquid-crystalline phosphatidylcholine bilayers). More lipids may be involved in folding intermediates or if second shells are perturbed by the protein. Therefore, it is conceivable that at $\mathrm{L} / \mathrm{P}<90$, OmpA molecules interact with each other when inserting and folding. A similar effect of high protein content on the rate of insertion into a lipid bilayer has been observed for a VDAC protein. ${ }^{30}$

\section{Dependence of insertion and folding on the lipid chain length}

Both, insertion and folding of OmpA into mildly curved lipid bilayers of LUVs of a short chain lipid such as $d i \mathrm{C}_{12} \mathrm{PC}$ are spontaneous in vitro. A steep dependence of the rate constants of OmpA folding on the hydrophobic thickness of the bilayer is observed. The energy barrier for insertion increases with increasing thickness of the lipid bilayer to a point at 14 or more carbon atoms where spontaneous insertion and translocation no longer occurs. However, folding of OmpA into thicker bilayers composed of $d i \mathrm{C}_{14} \mathrm{PC}, \mathrm{C}_{16} \mathrm{C}_{18: 1} \mathrm{PC}$, or $d_{i 2} \mathrm{C}_{18: 1} \mathrm{PC}$ was successful when they were highly curved in SUVs and the temperature was $>25^{\circ} \mathrm{C}^{8-11}$ This indicates that the activation energy for folding into SUVs is reduced, or equivalently, some of the energy needed for activation is provided by sonication and stored as curvature strain in SUVs. This is consistent with our observation of a $\sim 2.3$ times higher second-order rate constant when SUVs of $d i \mathrm{C}_{11} \mathrm{PC}$ were used instead of LUVs (data not shown).

The dependence of the folding kinetics of OmpA into phospholipid bilayers of different hydrophobic thickness immediately raises the question whether the transmembrane hydrophobic thicknesses of OmpA and of the phospholipids match each other. The length of the hydrophobic TM region of OmpA is $\sim 20 \AA,{ }^{31,32}$ similar to that of other TM $\beta$-barrels. ${ }^{33-35}$ In the crystal structure of OmpA with two molecules of $\mathrm{C}_{8} \mathrm{E}_{4}$ the two octyl chains cover most of the hydrophobic TM region of OmpA. They are in an all-trans conformation, while the acyl chains in fluid bilayers are more disordered. The hydrophobic thickness of $d i \mathrm{C}_{12} \mathrm{PC}$ bilayers is $19.5( \pm 1) \AA^{36}$ i.e. it matches that of OmpA very well. OmpA can also fold into bilayers of lipids with shorter chains, because the chains may be stretched in the vicinity of TMPs with longer hydrophobic length ${ }^{37}$ (reviews $^{38,39}$ ). The energy requirement for bilayer thickening is actually quite small up to the limit of full extension of the acyl chains. The energy cost of a 33\% increase in bilayer thickness, which corresponds to a $\sim 25 \%$ reduction of the molecular surface area, is only about $2 \mathrm{kT}$ per molecule. ${ }^{40,41} \mathrm{diC}_{14} \mathrm{PC}$ and di $\mathrm{C}_{18: 1} \mathrm{PC}$, which have hydrophobic thicknesses of $23( \pm 1) \AA$ and $27( \pm 1) \AA$, respectively, ${ }^{36}$ would have to be compressed to match the hydrophobic thickness of OmpA. Lewis \& Engelman ${ }^{42}$ demonstrated in a previous study that BR (with a hydrophobic thickness of $\sim 30 \AA^{15}$ ) remains well dispersed in bilayers with hydrophobic thicknesses ranging from $19.5 \AA$ to $34 \AA$. In their study, BR aggregation occurred in thick bilayers when the mismatch exceeded $6 \AA$. However, in thin bilayers a mismatch of up to $14 \AA$ was tolerated. Membrane thinning may not occur as readily as membrane thickening, because even $2-3 \%$ surface area increases destabilize the bilayer structure and break membranes. ${ }^{43}$

The selection of thinner membranes may provide a mechanism for targeting Omps to the outer rather than the inner membranes of Gram-negative bacteria. It is interesting to note that most Omps have relatively short hydrophobic TM regions (about 20-24 A), which is in contrast to the TM regions of $\alpha$-helix-bundle membrane proteins $(\sim 30-32 \AA)$ found in the inner membrane. The precise thickness of the hydrophobic core of the outer membrane is not known, but it is known that the outer membrane is highly asymmetric and contains mostly lipopolysaccharide (LPS) in the outer leaflet. LPS, which is not present in the inner membrane, has six fatty acyl chains (with predominantly 14 carbon atoms) that are linked to a glucosamine disaccharide backbone. Some of the fatty acyl chains in LPS are hydroxylated at carbon $3{ }^{44}$ It is possible that the shorter chains, the hydroxyl group and the glucosamine disaccharide backbone yield outer membranes with thinner hydrophobic cores than inner membranes consisting mostly of phospholipids with 16 and 18 carbon chains.

\section{Kinetics of secondary and tertiary structure formation}

When OmpA was folded into $d i \mathrm{C}_{12} \mathrm{PC}$ bilayers, the kinetics of tertiary structure formation and the kinetics of secondary structure formation had virtually identical second-order rate constants. In contrast, the second-order rate constant of the fluorescence kinetics was about five times greater. The fluorescence increase monitors the polarity change of the environment of the Trp residues of OmpA when they penetrate the lipid bilayer. Four out of the five Trp residues are located at the front end of the newly formed $\beta$-barrel. ${ }^{31,32}$ Therefore, the kinetics of Trp penetration are characterized 
by a greater rate constant than the rates of $\beta$-strand and $\beta$-barrel formation. However, none of the three methods used in this study indicated spontaneous folding of OmpA into LUVs of $\mathrm{diC}_{18: 1} \mathrm{PC}$ or $d i \mathrm{C}_{14} \mathrm{PC}$, but all methods report folding into LUV bilayers of short-chain phospholipids. Therefore, insertion and folding, as monitored by these methods appears to be driven by hydrophobic interactions with the lipid acyl chains. The increased surface curvature of SUVs results in more hydrophobic chain exposure than in less curved membranes. Surrey \& Jähnig ${ }^{10}$ have proposed that folding of OmpA is promoted by more frequent defects in highly curved SUVs. Both of these effects would lead to faster folding kinetics of OmpA in SUVs compared to LUVs, as observed by fluorescence and SDS-PAGE. Consistent with these ideas, thin lipid bilayers exhibit increased chain dynamics and higher bending flexibility, which will favor OmpA insertion and folding. Flexible bilayers will have transient sites of high curvature that may serve as nucleation sites for insertion and folding. Insertion and folding of Omps in vivo may also be accelerated by factors that reduce the lateral pressure in membranes and perhaps induce transiently increased local curvature in the outer membrane.

The synchronized formation of secondary and tertiary structure in transmembrane $\beta$-barrel proteins may be required to form a contiguous hydrophobic surface to insert into the hydrophobic core of the lipid bilayer. Such a mechanism is not necessarily required for soluble $\beta$-barrel proteins, since much of their surface remains exposed to water. In addition, penetration of the viscous membrane is a slow process. Therefore, much faster time constants (ranging from 4 seconds to 13 seconds) have been reported for the formation of $\beta$-strands in soluble $\beta$-barrels for example that of human fibroblast growth factor $1 .^{45}$

\section{Comparison with earlier results}

It is interesting to compare the kinetic results of this study with our earlier study on OmpA folding into $d_{i C_{18: 1}}$ PC bilayers of SUVs. ${ }^{11}$ As shown in Figure 2(b), OmpA folding into SUV bilayers of $d_{i} C_{18: 1} \mathrm{PC}$ follows a second-order rate law and may be approximated by a pseudo-first-order rate law. In our previous studies with SUVs of $d i \mathrm{C}_{18: 1} \mathrm{PC}$ at temperatures between $2{ }^{\circ} \mathrm{C}$ and $40^{\circ} \mathrm{C}$, several phases of OmpA folding could be observed, indicating several membrane-bound folding intermediates. ${ }^{11}$ The intermediates could be identified, because the folding process into bilayers of $d i \mathrm{C}_{18: 1} \mathrm{PC}$ (SUVs) was much slower especially at temperatures between $2{ }^{\circ} \mathrm{C}$ and $30^{\circ} \mathrm{C}$. We could characterize three membrane-bound intermediates in this previous work by time-resolved distance determinations by fluorescence quenching. ${ }^{12,13}$ The five Trp residues that are distributed over four TM segments of OmpA had specific distances from the center of the lipid bilayer in each of the folding intermediates. That analysis demonstrated that the membrane-spanning segments insert into the bilayer by a concerted mechanism. Folding experiments with $d i \mathrm{C}_{18: 1} \mathrm{PC}$ SUV bilayers at $30^{\circ} \mathrm{C}$ also revealed the formation of a semi-compact intermediate state of OmpA. ${ }^{11}$ This intermediate was characterized by an apparent molecular mass of $\sim 32 \mathrm{kDa}$ and locations of the translocated Trp residues close to the center of the lipid bilayer. ${ }^{12,13}$ The partial formation of tertiary structure ${ }^{11}$ upon translocation of these Trp residues across the bilayer, ${ }^{12,13}$ correlated with the observation of synchronized secondary and tertiary structure formation observed here, suggests that secondary structure is formed during insertion into the lipid bilayer. Therefore, the membrane-bound intermediates detected in our previous study very likely consist of largely incorrectly folded parts of OmpA exposed to the aqueous phase and mostly structured parts of OmpA in the hydrophobic core.

Although the present folding kinetics into bilayers of short-chain phospholipids are much faster and do not resolve folding intermediates, the correlation with our previous kinetic data ${ }^{11-13}$ provides evidence that the extent of $\beta$-sheet secondary structure formation in OmpA is directly coupled to the extent of OmpA insertion into the lipid bilayer. It is likely that the intermediates previously detected by time-resolved distance determinations ${ }^{12,13}$ in SUVs, also occur transiently when OmpA folds and inserts into LUVs. We therefore propose the following refined folding model. Upon urea dilution, OmpA first forms a hydrophobically collapsed state in water, which then interacts with the lipid bilayer. The structure of this intermediate has not been characterized in much detail. OmpA then penetrates the bilayer while the $\beta$-barrel is formed. When the Trp residues reach the center of the lipid bilayer and when the lipid bilayer structure is maximally perturbed, ${ }^{12,13}$ OmpA forms a semi-compact state that migrates at $32 \mathrm{kDa}$ if the sample is not boiled prior to loading on SDS-gels. ${ }^{11}$ This folding model relates our current observation of synchronized formation of secondary and tertiary structure to our previous results on the correlation of the translocation of the individual Trp residues and the appearance of a semi-compact folding intermediate. ${ }^{11-13}$

It is clear that the mechanism of folding described here differs from the two-stage model that is widely accepted to govern the folding of $\alpha$-helical bundle membrane proteins. $^{46}$ In that model, secondary structure formation (establishment of individual TM $\alpha$-helices) occurs in stage I and is distinct from tertiary structure formation (helix associations), which only occurs in stage II. The reason for these very different folding mechanisms must be the very different hydrogen bonding patterns in $\alpha$-helical and $\beta$-barrel TMPs. To transfer open hydrogen bonds into the hydrophobic environment of a lipid bilayer is energetically very unfavorable. ${ }^{1,47}$ Only fully hydrogen-bonded structures can exist when deeply inserted in lipid 
bilayers. A single $\alpha$-helix is internally fully hydrogen-bonded, but individual $\beta$-strands or even open $\beta$-sheets are not. We believe that the requirement for full hydrogen bonding of membraneinserted proteins is the origin of the requirement to mechanistically couple secondary and tertiary structure formation in OmpA and presumably all $\beta$-barrel TMPs. Individual $\beta$-strands and open $\beta$-sheets simply cannot exist as elementary TM building blocks of this class of TMPs. The smallest $\beta$-structured TM element that can exist in membranes is the $\beta$-barrel. In this sense, barrel formation in $\beta$-structured membrane proteins is equivalent to $\alpha$-helix formation in helical TMPs. Therefore, the reaction that we observed here with OmpA may be better compared to only stage I, TM helix formation, of helical TMPs rather than to the full folding process of helical bundle proteins. The kinetics of this first stage of the establishment of an $\alpha$-helix across membranes is difficult to study in as much detail, as done here for OmpA, because unfolded TM $\alpha$-helices cannot be kept in solution. Since $\beta$-barrel TMPs have much smaller average sequence hydrophobicities, they offer distinct technical advantages over helical TMPs for studies of the mechanistic details of this reaction. For example, $\beta$-barrel TMPs can be completely unfolded in aqueous denaturants such as urea or guanidium chloride and refolding into membranes may be studied from such states. We therefore believe that some fundamental aspects of our work on OmpA folding relates, not only to the folding of other $\beta$-barrel TMPs, but may also relate to stage I of the folding of helical TMPs.

\section{Methods}

\section{Determination of the rate law of the folding reaction}

To determine the order of OmpA folding of into membranes, we used the method of initial rates. Briefly, the rate of a reaction:

$$
A+B \rightarrow C
$$

is given by:

$$
\frac{\mathrm{d}[C](t)}{\mathrm{d} t}=k[A]^{n}(t)[B]^{m}(t)
$$

where $m+n$ is the order of the reaction and $k$ is the rate constant. When a set of experiments is performed, in which the rate of the reaction is monitored as a function of the initial concentration of reactant $A\left([A]_{0}\right)$ at the same initial concentration of reactant $B$, the initial rate is given by:

$$
\begin{aligned}
& \left(\frac{\mathrm{d}[C]}{\mathrm{d} t}\right)_{t=0}=\mathrm{const}[A]_{0}^{n} \\
& \text { i.e. } \operatorname{LN}\left(\left(\frac{\mathrm{d}[C]}{\mathrm{d} t}\right)_{t=0}\right)=n L N\left([A]_{0}\right)+L N(\text { const })
\end{aligned}
$$

with const $=k[B]_{0}^{m}$. A double logarithmic plot of the initial rate as a function of $[A]_{0}$ is linear and has a slope $n$, which is the order of the reaction with respect to $A$. The order $m$ of the reaction with respect to $B$ is deter- mined analogously from a double logarithmic plot of the initial rate as a function of $[B]_{0}$ and setting $k[A]_{0}^{n}=$ const. $^{48}$

The rate law for a second-order reaction such as the folding of protein into lipid bilayers is:

$\frac{\mathrm{d}\left[P_{\mathrm{F}}\right](t)}{\mathrm{d} t}=-\frac{\mathrm{d}[L](t)}{\mathrm{d} t}=-\frac{\mathrm{d}\left[P_{\mathrm{U}}\right](t)}{\mathrm{d} t}=k_{2 . \text { ord }}\left[P_{\mathrm{U}}\right](t)[L](t)$

$\left[P_{\mathrm{F}}\right](t)$ and $\left[P_{\mathrm{U}}\right](t)$ are, respectively, the concentrations of folded and unfolded protein and $[L](t)$ is the concentration of the lipid at time $t$ from initiation of the reaction. $k_{2 \text {.ord }}$ is the second-order rate constant.

To determine the second-order rate constants, we fitted the time courses to the integrated second-order rate law:

$$
\left[P_{\mathrm{F}}\right](t)=\frac{\left[P_{\mathrm{U}}\right]_{0}[L]_{0}\left(\exp \left\{\left(\left[P_{\mathrm{U}}\right]_{0}-[L]_{0}\right) k_{2 . \mathrm{ord}} t\right\}-1\right)}{\left[P_{\mathrm{U}}\right]_{0} \exp \left\{\left(\left[P_{\mathrm{U}}\right]_{0}-[L]_{0}\right) k_{2 . \mathrm{ord}} t\right\}-[L]_{0}}
$$

where $\left[P_{\mathrm{U}}\right]_{0}$, and $[L]_{0}$ are initial concentrations.

In fluorescence and circular dichroism experiments, the concentrations of folded and unfolded protein both contribute to the spectroscopic signal. Therefore, equation (4) becomes:

$$
\begin{aligned}
& S(t)=S_{\mathrm{L}}\left[P_{\mathrm{F}}\right](t)+S_{\mathrm{W}}\left[P_{\mathrm{U}}\right](t)+\text { const } \\
& \text { with }\left[P_{\mathrm{U}}\right](t)=\left[P_{\mathrm{U}}\right]_{0}-\left[P_{\mathrm{F}}\right](t)
\end{aligned}
$$

$S_{\mathrm{L}}$ and $S_{\mathrm{W}}$ are coefficients that describe the spectroscopic contribution of the folded and unfolded species to the fluorescence $\left(S_{\mathrm{L}}=F_{\mathrm{L}}, S_{\mathrm{W}}=F_{\mathrm{W}}\right)$ or circular dichroism signal $\left(S_{\mathrm{L}}=\mathrm{CD}_{\mathrm{L}}, S_{\mathrm{W}}=\mathrm{CD}_{\mathrm{W}}\right)$. const is a time-independent fitting parameter to account for background signals, for example from light scattering. In fits of the fluorescence data of Figure 2(a) to equation (5), the only free fit parameters were $k_{2 \text {.ord }}, F_{\mathrm{L}}, F_{\mathrm{W}}$, and const. The initial concentrations of unfolded OmpA and lipid are known and therefore fixed parameters.

\section{Purification of OmpA and preparation of LUVs}

OmpA was purified from E. coli in an unfolded form in $8 \mathrm{M}$ urea as described. ${ }^{8}$ Phospholipids (Avanti Polar Lipids, Alabaster, AB) were dissolved in chloroform, dried under a stream of nitrogen and in a desiccator under high vacuum to prepare thin films on the bottom of glass test tubes. The lipids were hydrated in $10 \mathrm{mM}$ borate buffer ( $\mathrm{pH} 10)$, with $2 \mathrm{mM}$ EDTA and dispersed by vortexing. After five cycles of freeze-thawing in liquid nitrogen and in a water bath at $35^{\circ} \mathrm{C}$, the liposomes were extruded nine times through a pair of $100 \mathrm{~nm}$ pore size polycarbonate membranes (Nucleopore, Pleasanton, CA) using a liposofast extruder (Avestin, Ottawa, Canada). LUVs were freshly prepared for each experiment.

\section{Kinetics of OmpA insertion and folding into membranes detected by SDS-gel electrophoresis}

Folding was initiated by mixing a small volume of a concentrated stock of denatured OmpA with LUVs in a large volume. Urea was diluted 12 -fold in this process. Samples of the reaction mixture were taken at different times after initiation of folding and an equal volume of $0.125 \mathrm{M}$ Tris buffer ( $\mathrm{pH} 6.8$ ), containing $4 \%$ (w/v) SDS, $20 \%(\mathrm{v} / \mathrm{v})$ glycerol and $10 \%(\mathrm{v} / \mathrm{v}) 2$-mercaptoethanol was added. SDS binds to both folded and unfolded OmpA and inhibits further folding. ${ }^{10,11}$ SDS-PAGE was 
performed as described, ${ }^{49,50}$ but without heat denaturation of the samples. The different electrophoretic mobilities of folded $\left(M_{\mathrm{r}}=30 \mathrm{kDa}\right)$ and unfolded OmpA $\left(M_{\mathrm{r}}=35 \mathrm{kDa}\right)$ were used to determine the fraction of folded OmpA by densitometry. A total of $17 \mu \mathrm{M}$ OmpA was incubated with lipid at selected lipid/OmpA ratios in $150 \mu \mathrm{l}$ of borate buffer $\left(10 \mathrm{mM} \mathrm{H}_{3} \mathrm{BO}_{3} / \mathrm{NaOH}(\mathrm{pH}\right.$ 10.0 ), containing $2 \mathrm{mM}$ EDTA) at $20^{\circ} \mathrm{C}$. No high molecular mass aggregates were detected at $\mathrm{pH} 10 .^{10}$ At $\mathrm{pH} 7$, some OmpA aggregated while the majority of OmpA folded correctly and showed the same dependence on the lipid concentration and lipid acyl chain length.

\section{Folding monitored by CD spectroscopy}

Far UV CD spectra of $3.1 \mu \mathrm{M}$ OmpA were recorded at $20^{\circ} \mathrm{C}$ as described ${ }^{14}$ at $20^{\circ} \mathrm{C}$ on a Jasco 600 spectropolarimeter using a $0.5 \mathrm{~mm}$ thermostated cuvette. Five scans were accumulated from $190 \mathrm{~nm}$ to $250 \mathrm{~nm}(205-250 \mathrm{~nm}$ in presence of $8 \mathrm{M}$ urea) with a response time of two seconds, a bandwidth of $1 \mathrm{~nm}$, and a scan speed of $10 \mathrm{~nm} \mathrm{~min}{ }^{-1}$. Background spectra without OmpA were subtracted. Time-based scans were carried out at $204 \mathrm{~nm}$ at a bandwidth of $1 \mathrm{~nm}$.

\section{Folding monitored by fluorescence spectroscopy}

Fluorescence spectra were recorded as described on a Spex Fluoromax spectrofluorometer. ${ }^{13}$ Fluorescence was detected in mega counts per second (Mcps) which are arbitrary fluorescence units. Fluorescence time courses were monitored at $330 \mathrm{~nm}$ with an excitation wavelength of $290 \mathrm{~nm}$, an excitation bandwidth of $2.25 \mathrm{~nm}$, an emission bandwidth of $5 \mathrm{~nm}$, an integration time of 0.1 second, and an increment of one second. Unless stated otherwise, the OmpA concentration was $1.14 \mu \mathrm{M}$. In kinetic experiments, refolding was initiated by fast hand mixing with a dead time of about ten seconds.

\section{Acknowledgements}

This work was supported by NIH grant GM51329 (to L.K.T.) and by DFG grant KL 1024/ 2-2 (to J.H.K.). We thank Dr Hans-Jürgen Apell, University of Konstanz, for his critical reading of the manuscript and useful discussions.

\section{References}

1. Engelman, D. M. \& Steitz, T. A. (1981). The spontaneous insertion of proteins into and across membranes: the helical hairpin hypothesis. Cell, 23, 411-422.

2. Huang, K. S., Bayley, H., Liao, M. J., London, E. \& Khorana, H. G. (1981). Refolding of an integral membrane protein. Denaturation, renaturation, and reconstitution of intact bacteriorhodopsin and two proteolytic fragments. J. Biol. Chem. 256, 3802-3809.

3. London, E. \& Khorana, H. G. (1982). Denaturation and renaturation of bacteriorhodopsin in detergents and lipid-detergent mixtures. J. Biol. Chem. 257, 7003-7011.

4. Popot, J. L., Gerchman, S. E. \& Engelman, D. M. (1987). Refolding of bacteriorhodopsin in lipid bilayers. A thermodynamically controlled two-stage process. J. Mol. Biol. 198, 655-676.

5. Kahn, T. W. \& Engelman, D. M. (1992). Bacteriorhodopsin can be refolded from two independently stable transmembrane helices and the complementary five-helix fragment. Biochemistry, 31, 6144-6151.

6. Booth, P. J. \& Curran, A. R. (1999). Membrane protein folding. Curr. Opin. Struct. Biol. 9, 115-121.

7. Dornmair, K., Kiefer, H. \& Jähnig, F. (1990). Refolding of an integral membrane protein, OmpA of Escherichia coli. J. Biol. Chem. 265, 18907-18911.

8. Surrey, T. \& Jähnig, F. (1992). Refolding and oriented insertion of a membrane protein into a lipid bilayer. Proc. Natl Acad. Sci. USA, 89, 7457-7461.

9. Rodionova, N. A., Tatulian, S. A., Surrey, T., Jähnig, F. \& Tamm, L. K. (1995). Characterization of two membrane-bound forms of OmpA. Biochemistry, 34, 1921-1929.

10. Surrey, T. \& Jähnig, F. (1995). Kinetics of folding and membrane insertion of a $\beta$-barrel membrane protein. J. Biol. Chem. 270, 28199-28203.

11. Kleinschmidt, J. H. \& Tamm, L. K. (1996). Folding intermediates of a $\beta$-barrel membrane protein. Kinetic evidence for a multi-step membrane insertion mechanism. Biochemistry, 35, 12993-13000.

12. Kleinschmidt, J. H., den Blaauwen, T., Driessen, A. \& Tamm, L. K. (1999). Outer membrane protein A of E. coli inserts and folds into lipid bilayers by a concerted mechanism. Biochemistry, 38, 5006-5016.

13. Kleinschmidt, J. H. \& Tamm, L. K. (1999). Timeresolved distance determination by tryptophan fluorescence quenching: probing intermediates in membrane protein folding. Biochemistry, 38, 4996-5005.

14. Kleinschmidt, J. H., Wiener, M. C. \& Tamm, L. K. (1999). Outer membrane protein A of E. coli folds into detergent micelles, but not in the presence of monomeric detergent. Protein Sci. 8, 2065-2071.

15. Pebay-Peyroula, E., Rummel, G., Rosenbusch, J. P. \& Landau, E. M. (1997). X-ray structure of bacteriorhodopsin at 2.5 angstroms from microcrystals grown in lipidic cubic phases. Science, 277, 1676-1681.

16. Subramaniam, S. \& Henderson, R. (2000). Molecular mechanism of vectorial proton translocation by bacteriorhodopsin. Nature, 406, 653-657.

17. Luecke, H., Schobert, B., Richter, H. T., Cartailler, J. P. \& Lanyi, J. K. (1999). Structure of bacteriorhodopsin at $1.55 \AA$ resolution. J. Mol. Biol. 291, 899-911.

18. Arora, A., Rinehart, D., Szabo, G. \& Tamm, L. K. (2000). Refolded outer membrane protein A of Escherichia coli forms ion channels with two conductance states in planar lipid bilayers. J. Biol. Chem. 275, 1594-1600.

19. Schäfer, U., Beck, K. \& Müller, M. (1999). Skp, a molecular chaperone of Gram-negative bacteria, is required for the formation of soluble periplasmic intermediates of outer membrane proteins. J. Biol. Chem. 274, 24567-24574.

20. Chen, R. \& Henning, U. (1996). A periplasmic protein (Skp) of Escherichia coli selectively binds a class of outer membrane proteins. Mol. Microbiol. 19, 1287-1294.

21. Behrens, S., Maier, R., de Cock, H., Schmid, F. X. \& Gross, C. A. (2001). The SurA periplasmic PPIase lacking its parvulin domains functions in vivo and has chaperone activity. EMBO J. 20, 285-294. 
22. Lazar, S. W. \& Kolter, R. (1996). SurA assists the folding of Escherichia coli outer membrane proteins. J. Bacteriol. 178, 1770-1773.

23. Tamm, L. K., Arora, A. \& Kleinschmidt, J. H. (2001). Structure and assembly of $\beta$-barrel membrane proteins. J. Biol. Chem. 276, 32399-32402.

24. Schweizer, M., Hindennach, I., Garten, W. \& Henning, U. (1978). Major proteins of the Escherichia coli outer cell envelope membrane. Interaction of protein II with lipopolysaccharide. Eur. J. Biochem. 82, 211-217.

25. Sugawara, E., Steiert, M., Rouhani, S. \& Nikaido, H. (1996). Secondary structure of the outer membrane proteins OmpA of Escherichia coli and OprF of Pseudomonas aeruginosa. J. Bacteriol. 178, 6067-6069.

26. Vogel, H. \& Jähnig, F. (1986). Models for the structure of outer-membrane proteins of Escherichia coli derived from Raman spectroscopy and prediction methods. J. Mol. Biol. 190, 191-199.

27. Kleinschmidt, J. H. \& Tamm, L. K. (2002). Structural transitions in short-chain lipid assemblies studied by ${ }^{31}$ P-NMR spectroscopy. Biophys. J. 83, 994-1003.

28. Booth, P. J., Riley, M. L., Flitsch, S. L., Templer, R. H., Farooq, A., Curran, A. R. et al. (1997). Evidence that bilayer bending rigidity affects membrane protein folding. Biochemistry, 36, 197-203.

29. Shin, Y. K., Levinthal, C., Levinthal, F. \& Hubbell, W. L. (1993). Colicin E1 binding to membranes: time-resolved studies of spin-labeled mutants. Science, 259, 960-963.

30. Xu, X. \& Colombini, M. (1997). Autodirected insertion: preinserted VDAC channels greatly shorten the delay to the insertion of new channels. Biophys. J. 72, 2129-2136.

31. Pautsch, A. \& Schulz, G. E. (1998). Structure of the outer membrane protein A transmembrane domain. Nature Struct. Biol. 5, 1013-1017.

32. Pautsch, A. \& Schulz, G. E. (2000). High-resolution structure of the OmpA membrane domain. J. Mol. Biol. 298, 273-282.

33. Ferguson, A. D., Hofmann, E., Coulton, J. W., Diederichs, K. \& Welte, W. (1998). Siderophoremediated iron transport: crystal structure of FhuA with bound lipopolysaccharide. Science, 282, 2215-2220.

34. Hirsch, A., Breed, J., Saxena, K., Richter, O. M., Ludwig, B., Diederichs, K. \& Welte, W. (1997). The structure of porin from Paracoccus denitrificans at $3.1 \AA$ resolution. FEBS Letters, 404, 208-210.

35. Vogt, J. \& Schulz, G. E. (1999). The structure of the outer membrane protein OmpX from Escherichia coli reveals possible mechanisms of virulence. Struct. Fold. Des. 7, 1301-1309.
36. Lewis, B. A. \& Engelman, D. M. (1983). Lipid bilayer thickness varies linearly with acyl chain length in fluid phosphatidylcholine vesicles. J. Mol. Biol. 166, 211-217.

37. de Planque, M. R., Greathouse, D. V., Koeppe, R. E., II, Schafer, H., Marsh, D. \& Killian, J. A. (1998). Influence of lipid/peptide hydrophobic mismatch on the thickness of diacylphosphatidylcholine bilayers. A ${ }^{2} \mathrm{H}-\mathrm{NMR}$ and ESR study using designed transmembrane $\alpha$-helical peptides and gramicidin A. Biochemistry, 37, 9333-9345.

38. Killian, J. A. (1998). Hydrophobic mismatch between proteins and lipids in membranes. Biochim. Biophys. Acta, 1376, 401-415.

39. Marsh, D. (1990). Lipid-protein interactions in membranes. FEBS Letters, 268, 371-375.

40. Parsegian, V. A., Fuller, N. \& Rand, R. P. (1979). Measured work of deformation and repulsion of lecithin bilayers. Proc. Natl Acad. Sci. USA, 76, 2750-2754.

41. Lis, L. J., McAlister, M., Fuller, N., Rand, R. P. \& Parsegian, V. A. (1982). Measurement of the lateral compressibility of several phospholipid bilayers. Biophys. J. 37, 667-672.

42. Lewis, B. A. \& Engelman, D. M. (1983). Bacteriorhodopsin remains dispersed in fluid phospholipid bilayers over a wide range of bilayer thicknesses. J. Mol. Biol. 166, 203-210.

43. Kwok, R. \& Evans, E. (1981). Thermoelasticity of large lecithin bilayer vesicles. Biophys. J. 35, 637-652.

44. Ferguson, A. D., Welte, W., Hofmann, E., Lindner, B., Holst, O., Coulton, J. W. \& Diederichs, K. (2000). A conserved structural motif for lipopolysaccharide recognition by procaryotic and eucaryotic proteins. Struct. Fold. Des. 8, 585-592.

45. Samuel, D., Kumar, T. K., Balamurugan, K., Lin, W. Y., Chin, D. H. \& Yu, C. (2001). Structural events during the refolding of an all $\beta$-sheet protein. J. Biol. Chem. 276, 4134-4141.

46. Popot, J. L. \& Engelman, D. M. (1990). Membrane protein folding and oligomerization: the two-stage model. Biochemistry, 29, 4031-4037.

47. White, S. H. \& Wimley, W. C. (1999). Membrane protein folding and stability: physical principles. Annu. Rev. Biophys. Biomol. Struct. 28, 319-365.

48. Atkins, P. W. (1998). Physical Chemistry, 6th edit., W. H. Freeman, New York.

49. Laemmli, U. K. (1970). Cleavage of structural proteins during the assembly of the head of bacteriophage T4. Nature, 227, 680-685.

50. Weber, K. \& Osborne, M. (1964). The reliability of molecular weight determinations by dodecyl sulfate-polyacrylamide gel electrophoresis. J. Biol. Chem. 244, 4406-4412. 